\title{
Políticas de formação continuada e a prática pedagógica do professor de Filosofia
}

\author{
Zita Lago Rodrigues $^{7}$
}

Resumo: Apresenta reflexões sobre as políticas de formação docente, na perspectiva da complexidade da sociedade contemporânea, propondo a superação das fragmentações e das exclusões seletivas na arquitetura curricular e pedagógica da educação. Contextualiza a importância da busca por posições teórico-práticas englobantes e de melhor compreensão sobre os fenômenos socioculturais e pedagógicos nos quais se inserem a educação e a formação docente. Explicita o papel do professor de Filosofia em suas práticas pedagógicas como exercício da dúvida metódica, cuja importante tarefa epistemológica não pode ser desenvolvida sem referência a uma antropologia fundante e a uma axiologia geral sobre o agir humano nos dimensões éticas, políticas, científicas e pedagógicas, devendo ser efetivada em reflexões sistematizadas e aprofundadas que "pensem seu tempo", não se submetendo a coerções e coações de qualquer natureza. Pressupõe a necessidade do pensamento complexo e da ação comunicativa, reflexiva e situada como forma e exercício cotidiano do "fazer filosofia" na ação pedagógica do cotidiano escolar.

Palavras-chave: Professor de Filosofia; formação continuada; prática docente; complexidade; reflexibilidade.

\section{Formation policy continuation and practics of pedagogy philosophy educator}

Abstract: It presents reflections on teacher education policies, in view of the complexity of contemporary society, proposing to overcome fragmentation and selective exclosures in curricular and pedagogical education. Contextualizes the importance of searching for positions encompassing theoretical and practical understanding of the phenomena in which social, cultural and pedagogical fall education and teacher training. Explains the role of professor of philosophy in their teaching as an exercise of methodical doubt, whose epistemological important task can not be developed without reference to anthropology and a founding general axiology of human action in ethical, political, scientific and educational, and should be conducted in-depth and systematic reflections that "think time", not submitting to coercion and coercion of any kind. Presupposes the need for complex thought and action communicative, reflective and situated so as daily exercise and "doing philosophy" in the pedagogical action of the school routine.

${ }^{7}$ Doutora em Educação (WU/USA-UFRJ). Docente visitante da ULHT-Lisboa-Port. E-mail: zitalago@yahoo.com.br. 
Key words: Professor of Philosophy; continuing education; teaching practice; complexity; reflectivity.

Submetido em: dezembro de 2012.

Aprovado em: fevereiro de 2013.

\section{Introdução}

No limiar de uma era global vislumbrando algo que já está presente, porém ainda duvidando suficientemente do passado para imaginarmos um futuro (Santos, 1987), necessitando de mudanças e transformações importantes para a ultrapassagem de alguns modelos e visões de homem, mundo, sociedade e educação que, através dos ethos, dos princípios e normas estratificadas se arraigaram nas culturas, cabem indagações sobre as formas de (re)configurações exigidas para demarcar tais transformações e mudanças. São indagações sobre:

-“como se delinearão os enfrentamentos às demandas dos complexos tempos contemporâneos e de suas decorrências?"

-“Quais princípios orientarão tais mudanças, de modo especial na escola e instâncias educativas, uma vez que os horizontes ainda são nebulosos?"

Dominados por uma lógica cruel de restrição e de reatividade ao novo, não raro, a perpetuação e a sacralização de alguns princípios, valores e crenças, determinados por elites seletivas e excludentes, tem se manifestado diuturnamente nos componentes que sustentam a escola e os sistemas educativos, através das fechadas arquiteturas dos currículos escolares, das metodologias de ensino, das formas de avaliação e, de modo especial, dos programas de formação docente em curso na maioria das instituições e dos sistemas de ensino, com fortes repercussões nas práticas pedagógicas do cotidiano escolar.

O afastamento e não a total negação de tais princípios estratificados e conservadores exige a abertura e a aceitação de ideias inovadoras, dinâmicas e pró-ativas, condizentes com os reptos da contemporaneidade e com as demandas de um futuro célere que chega e se apresenta desafiador e com valores outros do que aqueles que nos trouxeram até aqui, com suas certezas, verdades prontas e nomenclaturas paradigmáticas reveladoras de princípios de poder, dominação e estabilidade securizante aos grupos dominantes, que se estabelecem, regulam, determinam e estabelecem as verdades e as certezas.

Entre os educadores tem sido constante um ponto comum de que os elementos historicamente constituídos, importantes sob um ponto de vista da organização da sociedade 
moderna ocidental, defrontados com as novas bases materiais que caracterizam a reestruturação produtiva e a economia globalizada (Kuenzer, 2000) e as tecnologias de informação e comunicação em processo contínuo de expansão e inovação, expõem de forma quase patética a irrelevância e a obsolescência da escola atual e a imutabilidade dos sistemas educacionais reativos às reformas e às exigências de um mundo cada vez mais complexo, colaborativo e multifacetário. Nesse sentido, reforçamos o pensamento de Litwin (2001), ao considerar que:

Existe um consenso cada vez mais generalizado, segundo o qual a escola não está cumprindo satisfatoriamente a função de formar as futuras gerações, nas capacidades que irão requerer o desenvolvimento do cidadão em uma sociedade de rápidas mudanças. Ao mesmo tempo, não existe consenso sobre quais devem ser essas capacidades e quem deve ser responsável por sua difusão. (LITWIN, 2001, p. 153)

É o paradoxo do mundo globalizado, da evasão de responsabilidades, da inércia e do descompromissamento com as mudanças em suas inusitadas consequências, influenciando estados, sistemas e poderes constituídos aos quais se têm direcionado as demandas educacionais presentes, frutos das complexidades paradigmáticas atualmente em voga quando se trata do educar-se e do educar o homem e as sociedades, de modo especial na instituição escolar formal.

\section{Uma educação reflexiva e filosófica para a complexidade. No que consiste?}

Mediante tais paradoxos, contradições e desafios, e sustentadas por bases teóricas alternativas, surgem proposições de uma educação voltada para a reflexibilidade e a complexidade, definida por Moraes (1997) como:

A identificação de novos cenários nos leva a compreender que somos cidadãos do
mundo e que temos o direito de estarmos suficientemente preparados para nos
apossarmos dos instrumentos de nossa realidade cultural, para que possamos
participar do mundo [e numa cosmovisão superadora] termos uma compreensão do
mundo mais holística, global, sistêmica, que enfatiza o todo e não apenas as partes
(...), reconhece a interconectividade, a interdependência e a interatividade de todos
os fenômenos da natureza e o perfeito entrosamento dos indivíduos e das
sociedades em processos cíclicos (...), cheios de energia, em movimento, [como]
sistemas vivos, abertos e em movimentos flutuantes (...). (Moraes, 1997, p. 135)

Conforme Morin (2001a) a primeira vista a complexidade é um tecido - complexus $=$ o que é tecido em conjunto - com constituintes heterogêneos inseparavelmente associados, colocando o paradoxo do uno e do múltiplo, dizendo ser a complexidade efetivamente o tecido de acontecimentos, ações, interações, retroações, determinações e acasos que constituem o universo fenomenal contemporâneo, o que gera a necessidade de clarificar e distinguir as operações necessárias à inteligibilidade de tais fenômenos, visualizando-os em 
sua integralidade.

Portanto, falar de uma educação para a reflexibilidade, como propõe Favaretto (apud Arantes, 1995) e para a complexidade, conforme propõe Morin (2001), envolve considerar em que condições o fenômeno da educação e da formação docente vincula-se, em interações e ações, ao exercício prático de tal possibilidade na escola contemporânea. Portanto, v ale ressaltar o pensamento de Viegas Fernandes (2001, p. 20), segundo o qual:

O paradigma educacional vigente (unidimensional, monocultural e
compartimentado disciplinarmente) está articulado com o paradigma científico
dominante (fundado na especialização, na atomização, na compartimentação dos
conhecimentos e na racionalidade instrumental). Ambos são responsáveis pelo
modelo civilizacional contemporâneo (globalização neoliberal) que tem ampliado
as desigualdades e as exclusões sociais, agravado os desequilíbrios entre culturas e
os problemas ecológicos (que envolvem os seres biótipos e abiótipos).

Isto justificaria, em parte, a atual inadequação do paradigma cientificista-racionalista da modernidade, com suas bases de sustentação teórico-epistemológicas de forte cunho racionalista, levantando a necessidade de entrever bases paradigmáticas mais centradas na busca, no perquirimento, na investigação, nas incertezas, na incompletude, na reflexibilidade e nas possibilidades inusitadas em acordo com o pensamento moriniano, ou seja, em caminhos que, ao abandonar a lógica clássica racionalista, incluam conceitos inovadores, convivendo com a transgressão, o inusitado e a criação de possibilidades diferenciadas para conhecer, saber e fazer em suas aplicabilidades práticas. (MORIN, 2002).

Nesse sentido não estaríamos partindo do nada, do vazio, diz Morin (2002), mas sim das manifestações e sinais paradigmáticos da crise dos princípios racionalistas, sendo que a irrupção do paradigma da complexidade traria consigo os referenciais para a superação das patologias e aspectos inadequados do referido modelo e de suas nefastas consequências, exigindo a emergência de diálogos trans e metadisciplinares entre as ciências, constatando-se que “(...) o progresso da retomada de consciência das realidades complexas ocorrido após o desmoronamento do dogma determinista requer um pensamento e um método capazes de religá-las" (Morin, 2000, p. 107).

A riqueza do pensamento moriniano ao considerar a urgência da superação das visões fragmentárias, dualistas e separativas, características do modelo científico dominante, envolve todos os fenômenos da vida humana e, de modo especial, a educação escolarizada e seus desdobramentos na formação do homem, das sociedades e das suas estruturas constitutivas, historicamente fundadas sobre dicotomias excludentes.

A importância de buscarmos posições teórico-práticas mais sistêmicas e englobantes (Lago Rodrigues, 2003), para uma melhor compreensão dos fenômenos em suas múltiplas 
naturezas e, de modo especial, dos fenômenos socioculturais e pedagógicos, nos quais se inserem a educação e a formação docente, agregam-se a pensares de autores como Morin (2000, 2001, 2002), Santos (1987), Vilasante (2002), Favareto (apud Arantes, 1995), Severino (1996) entre outros, e propõem que se estabeleçam fundamentos para uma educação voltada para a reflexibilidade, a totalidade e a complexidade, envolvendo propostas mais esclarecedoras sobre a formação docente e mais adequadas aos reptos da contemporaneidade.

A modalidade complexa, concomitantemente com o paradigma emergente definido por Santos (1987), apresenta aos institutos legais voltados à formação docente evidências da emergencialidade de profundas transformações. Touraine (2006) enuncia a relevância de um novo paradigma como um processo que permita proceder a dissolução dos mecanismos de pertença a grupos e a instituições que perenizem de forma linear suas verdades e certezas, mantendo os indivíduos prisioneiros de valores, crenças e mapeamentos mentais, normas e determinações que os fragilizam e os mantém impotentes em dependências subservientes e guetos cristalizadores, impedindo-as de gerir seus destinos, de pensar por si e sobre suas realidades contextuais e de assumir riscos e responsabilidades emancipatórias de cunho ético, social, ecológico e humanizante.

Nos processos de formação docente com base em uma educação voltada para a reflexibilidade filosófica e para a complexidade o forte desafio será de que, sem deixar de contemplar as normativas e determinações legais que os fundamentam, seja possível superar as visões disciplinares presentes nos currículos formais e, estabelecendo interfaces construentes, permita promover rupturas com os tópois (lugares de segurança), indicando horizontes de transformação. E, superando os próprios u-topós (as utopias, tidas como lugares possíveis), estabelecer algo como as prótopias, seria sugerir a condição de colocar-se a caminho das mudanças e das transformações urgentes e necessárias no campo da formação docente.

A prótopia constitui-se em um neologismo que, no entendimento de Almeida Filho (2007), surge do próprio termo utopia, mas precedido pelo prefixo pro, nos situa numa condição de pró-atividade - a caminho das possibilidades, em ação, no caminho. Seria o caminho da atuação constante e em movimentos efetivos de substituição das formas tradicionais das modalidades de formação docente, abrindo o "novo lugar", não da verdade pronta, mas da constituição de pesquisas, perquirimentos, histórias e relatos de vida, inspirações superadoras e bases teórico-epistemológicas mais condizentes com o desenvolvimento de sujeitos pertencentes à atual galáxia imprecisa, em busca do 
entendimento dos significados, dos sentidos e voltados a uma educação não excludente.

Uma educação voltada para a reflexibilidade e a complexidade e preocupada com o atendimento das gritantes demandas da sociedade hodierna deverá apresentar uma arquitetura curricular contributiva a emancipação e a autonomia dos sujeitos, aos desempenhos cidadãos, ao êxito e ao sucesso profissional situados de forma ética e estética, em cenários contextualizados e abertos, flexíveis e dialogais, nos quais a razão instrumental ceda lugar e dialogue com a razão comunicativa (Habermas, 1989).

Uma arquitetura curricular de tal nível, muito mais do que saberes e certezas, presentificará a incerteza, o perquirimento, a busca interconectada, a pertença à condição humana, incompleta e processual e o acolher dos diferentes, das vozes dissonantes, dos olhares desafiadores, do entrelaçamento entre o senso-comum e a ciência (Santos, 1987) e a pregnância da renovação de valores, de princípios e ações capazes de relativizar aquilo que é arcaico e sustentar o que possa, renovando-se, renovar a vida, a pessoa e a sociedade em busca da convivência, da paz, da fraternidade e da solidariedade universais, as quais não estão explicitadas em nenhum currículo atual de formação de profisssionais docentes.

\section{E a prática pedagógica do professor de filosofia nesse contexto complexo?}

Visando responder a pergunta sobre os desafios da prática filosófica no mundo contemporâneo, não é suficiente a resposta lacônica de que a Filosofia se constitua em “fomento à uma atitude crítica e reflexiva". Talvez a utilidade e funcionalidade da filosofia possam revelar-se de modo mais eficaz se a aplicarmos, como crítica e reflexão, sobre os incertos problemas concretos do mundo hodierno. Apesar disto, com os procedimentos do filosofar contemporâneo parece-nos ainda estarmos distanciados de uma atitude de reflexibilidade e de um criticismo conseqüente, que permita melhorar o entendimento sobre os complexos fenômenos que permeiam a vida em sociedade e os contextuais meandros da vida na pólis.

Este é um ponto de partida para a pressuposição de que, entre os desafios contemporâneos da razão filosófica e da prática pedagógica do professor de Filosofia, estejam temas ou problemas a serem abordados e desenvolvidos de modo enfático tratando das questões ligadas ao desenvolvimento sociopolítico, econômico, cultural, pedagógico, ecológico e educacional, dos sujeitos e das sociedades.

Porém, o individualismo contemporâneo parece-nos absurdamente inconseqüente, imediatista e simplista para voltar-se de modo sério às questões que digam respeito a uma 
realidade amplamente envolvente, de modo ético e responsável, ampliando ao máximo as possibilidades de escolha para o homem e as instituições colocadas como inerentes a vida em sociedade. Essa reflexão e crítica, pela profundidade ética, solidária e complexa dela exigida, necessita embasar-se em eficazes formas de cooperação, colaboratividade e qualidade sobre os modos como se vive, se diz, se divulga, se produz e se pensa, cujos reflexos serão sentidos nas instituições e nas organizações de toda e qualquer natureza.

Na verdade, parece-nos que nos tempos atuais, a situação do pensar filosófico é de muito maior solidariedade com as Ciências e, de modo particular com as Ciências Humanas, do que aquele ocorrido no contexto da modernidade ocidental, diz Severino (1996). Porém, a Filosofia não deve entender-se como uma ontologia geral absoluta, em perspectivas metafísicas autônomas e definidoras do real; nem poderá impor-se como competidora das Ciências, disputando-lhe os terrenos. Muito mais necessita constituir-se em uma espécie de antropologia, buscando o sentido da existência humana em sua historicidade social, cultural e pedagógica, cabendo ao professor de Filosofia estabelecer estas interfaces em seu fazer docente.

Ao tomarmos a perspectiva de Severino (1996, p. 79) no entendimento do processo do filosofar "como expressão radicalizadora (de raiz), enquanto atividade simbolizadora do próprio conhecimento, da busca de esclarecimento do sentido da existência humana (...)", pressupomos que deva ocorrer por parte do professor de Filosofia um entendimento sobre os procedimentos do conhecer filosófico e de seu exercício, enquanto capacidade de pensar, refletir e esforçar-se para a convergência dos olhares e dos estudos, de modo englobante e radical (de raiz) visando encontrar o sentido do sentido das coisas, dos fenômenos e do existir humanos. Existir entendido como ação sobre dados objetivos da natureza física, frente aos outros homens e frente às condições das produções subjetivas, mensuradas histórica, simbólica e pedagogicamente.

Tais mediações concretamente efetuadas no campo de ação humana, pressupõem um contínuo construir, devir, pensar e fazer o real, em práticas políticas e pedagógicas, situadas e contextualizadas em suas temporalidades históricas, políticas e sociais. Nesses contextos a Filosofia precisa operar levando em conta as contribuições das Ciências, as quais se desdobram igualmente no sentido de esclarecer os diversos aspectos, necessariamente múltiplos, do viver humano. No atual contexto as ligações da Filosofia ocorrem muito mais com as Ciências Humanas, mas não se deve descuidar das relações com as demais Ciências, nas quais ocorrem celeremente a proposição de novas teorias, nem sempre constitutivas de 
novos paradigmas, mas não menos desestabilizadoras de certezas securizantes.

O Relatório da Comissão Gulbenkian sobre a Reestruturação das Ciências Sociais (2002) aponta como função atual das Ciências Humanas, entre elas a Filosofia, a busca de pensares e fazeres trans e metadisciplinares, cujas características se voltem a:

- superação dos racionalismos absolutos e dos materialismos vazios;

- desestruturação da teleologia das certezas históricas;

- descentralização das idolatrias do progresso e do desenvolvimento indiscriminado e irrefletido;

- superação das empirias relativistas e a crítica e superação dos radicalismos reducionistas, os quais caracterizaram a modernidade objetiva;

- superação das exclusões e seletividades próprias de outros momentos históricos, buscando levar os sujeitos a assim se constituírem, estudando e refletindo sobre si próprios e sobre as estruturas sociais, políticas, econômicas e pedagógicas estabelecidas, situando-se como atores e protagonistas e não mais como meros expectadores dos processos e de seus resultados nem sempre humanizantes.

Essa perspectiva de busca de focos metatransdisciplinares sobre o saber e o conhecimento, não deixa de ser um esforço da razão inquieta, ávida de esclarecimento, exigindo que a Filosofia não deixe de exercer sua função de reflexibilidade crítica sobre essa mesma realidade em constante mutação e reversibilidade, na tentativa de buscar e constituir perspectivas de ação e de vida construentes.

De acordo com H. Arendt (1988) a condição humana é vida dada ao homem como possibilidade; ele não só tem a vida, mas deverá arcar com ela, ou seja, fazer alguma coisa com a vida que lhe é entregue, tornando-se "acontecimento humano". Este acontecer se daria sob as formas de "vida ativa e vida contemplativa". Na vida contemplativa, o homem tem a possibilidade da compreensão a qual ocorre sobre três possibilidades: pensar, querer e julgar. Na vida ativa, o homem apresenta também três condições: $\underline{\text { a vida biológica, a mundaneidade e }}$

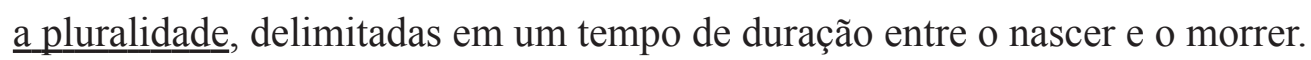

Nesse sentido, como constitutivo da vida contemplativa e como vida ativa, H. Arendt (1988) entende que o ser é entregue ao homem e ele só se realizará como tal se puser em andamento (em prática) essa contemplação e atividade, do contrário perderia sua própria humanidade. Isto por si só justificaria a proposição das "prótopias activas" e das ações motivadoras de práticas mais contextualizadas e em acordo com as instáveis bases situacionais do contemporâneo. 
Entendemos, portanto, em considerações concludentes, não herméticas, mas reflexivas e dialeticamente situadas, que a Filosofia no momento atual, seria contemplação - enquanto pensar, querer e julgar; e atuação - enquanto reflexibilidade e exercício radical da razão, fenomenológica e hermeneuticamente entendida como capacidade de interpretação e compreensão do próprio sentido da existência humana e da sua relação com a realidade, em posições mediadoras de uma formação e de uma educação que completem o sentido verdadeiramente humano do humano no homem.

Estaria, portanto posto aí o maior de todos os desafios à Filosofia no mundo contemporâneo: contemplar e atuar, como mediadora no processo histórico, sociopolítico, cultural e pedagógico que se apresente ao homem e que assim o desafie sempre a ser mais!

Os atuais tempos são difíceis. Difíceis, não somente no sentido prático, mas difíceis também no sentido de se esclarecer o papel a ser exercido pela nossa racionalidade, na complexidade das questões que lhe estão postas e pela exigência de se construírem identidades específicas à função do filosofar.

Os séculos anteriores caracterizaram-se por "muitas certezas" entre elas a de que, pela razão, o homem se libertaria de todas as formas de opressões. O atual momento é de "muitas dúvidas e poucas certezas" entre elas a de que essa razão instrumental cientificista nos legou sim inúmeros avanços, mas nos legou muitos mais problemas e questionamentos, caracterizando assim a urgente necessidade de reformulação dessas racionalidades.

Parece não restar dúvida de que, enquanto tributária da tradição clássica, a Filosofia deve manter seu caráter humanizante, interativamente posto na busca da liberdade e realização humanas, com o compromisso originário de vincular-se às verdades que a fundamentam.

O quadro atual em que se situa a crise das Ciências Humanas e da razão ocidental, permite mais fecundamente entender os impasses da Filosofia e do processo formativo do homem, sendo necessário (re)pensar-se o papel dessa mesma razão nesse contexto de crise global que assola a humanidade no contemporâneo.

Habermas (1989) aparece nesse contexto de crise da razão, com seu conceito de racionalidade comunicativa, ao esclarecer que o que se encontra esgotado não é a razão como tal, mas aquela razão que se expressa de modo reducionista, na racionalidade cognitivoinstrumental, serva da técnica e da tecnologia desumanizante e simplificadora.

Na teoria da ação comunicativa Habermas (1989) supõe que está a ocorrer "um déficit de racionalidade", o qual dificulta o desenvolvimento de uma racionalidade comunicativa 
suficiente e situada e nos apresenta uma alternativa ilustrada para pensar o presente e o futuro, sem nos entregarmos de modo definitivo aos tecnocratismos e reducionismos radicais, que tem levado as sociedades e os homens à hipertrofia da racionalidade comunicativa, do diálogo e da ação solidária, beirando a barbárie social, cujos efeitos estão a ser demonstrados cotidianamente e fazem o sucesso das mídias massificadoras, com impactos e repercussões na ação profissional cotidiano do educador.

A proposição da racionalidade habermasiana, comunicativa e social, possibilita ao professor de Filosofia e ao homem contemporâneo não perder a unidade de princípios universais (como a solidariedade, a eqüidade, a comunicação e o diálogo), resgatando a particularidade das diferenças contingenciais e históricas com as quais a Filosofia deve deparar-se cotidianamente, revelando a possibilidade da presentificação de sujeitos dialógicos e colaborativos e supondo a exigência de uma mudança paradigmática, deslocando o foco da investigação dessa racionalidade analítico-instrumental para uma racionalidade comunicativa e dialogal.

Pressupõe Habermas (1989) que o ponto de partida dessa ação filosóficocomunicativa teria a linguagem como meio para coordenar a ação, tornando-se o "locus" de uma racionalidade mais ampla e mais condizente com os desafios atuais postos à razão humana.

No pensar habermasiano a ambigüidade constitutiva do processo de modernização ocidental, pelo seu duplo aspecto de racionalização: do mundo vivido e dos subsistemas da sociedade, deveria ser repensado. Em nosso modo de entender, a distinção entre as duas formas de integração societária - integração social e integração sistemática - permite a análise das estruturas e tipos de racionalidade embutidos nas duas dimensões de sociedade e de educação, diagnosticando as crises e as patologias pedagógicas que as afetam no atual nível de desenvolvimento do conhecimento, do saber e das ciências.

Situa-se aí mais um desafio ao filosofar contemporâneo: a abertura às diversificadas possibilidades do saber, para o qual não basta o espírito de análise, mas se faz necessária a capacidade de sínteses - sínteses emancipatórias, reflexivas e mais dialogais.

Se entendermos com Husserl (1965, p. 72) que "Não é das filosofias que se deve partir no impulso da investigação, mas sim das coisas e dos problemas", teremos a clara lição de que, entre os desafios contemporâneos do filosofar, devemos nos dirigir, além dos conceitos ou das teorias doutrinárias, para as bases práticas e fundantes das crises sócioculturais-econômicas-políticas-pedagógicas e de valores, do atual momento histórico na 
sociedade ocidental.

Entendemos serem muitas as doutrinas filosóficas que se sucedem na História, sendo que o homem cultiva a esperança de que o fracasso desta ou daquela teoria seja substituído por uma nova teoria, ou por algo que a renove. Entender a Filosofia como um mero embate de linhas teóricas que se sucedem umas às outras é empobrecimento da tarefa filosófica, em especial no momento atual, em que suas forças necessitam ser vistas num contexto dinâmico, esclarecedor e questionador das realidades em todo seu entorno. Está justamente nesse questionamento reflexivo e prático sobre a realidade, conforme Von Zuben (1992, p. 24), o “cerne do labor filosófico, ou o élan da razão interrogativa, orientando-se na busca da verdade, angustiando-se pelo exercício do pensar, do questionar e do perquirir a realidade vigente".

Carneiro Leão (1977) entende que o homem contemporâneo tenta fugir do pensar, por isto deixa-se envolver tanto pelas tecnocracias vigentes e seus encantos pérfidos e sedutores e diferencia o chamado "pensamento calculante - a técnica - do pensamento de sentido - a Filosofia" (1977, p. 52-54), ao pressupor que:

(...) o pensamento de sentido não é algo fortuito ou dado gratuitamente; impõem esforço, serenidade de exercício, persistência e paciência, sem ser necessário para isto que voemos para espaços das estrelas [e, para que os desafios do pensar filosófico contemporâneo estejam sendo enfrentados] (...) basta ficarmos na proximidade de nossos empenhos e desempenhos, deixando-nos conduzir pelo que nos afeta aqui e agora.

\section{Para não concluir}

Isto posto, fazem-se necessárias algumas considerações para não concluir, mas para continuarmos a presente reflexão sobre as políticas de formação continuada e a prática pedagógica do professor de Filosofia no contemporâneo, cientes que:

- o exercício filosófico está longe de ser um exercício meramente especulativo;

- esse exercício tem origem histórica definida, a qual não deve ser perdida de vista, mas não deverá ser o centro das especulações;

- o célere desenvolvimento cientifico, fruto da técnica e da tecnologia contemporâneas, está ainda longe de justificar a superação da necessidade do "fillosofar";

- a cumplicidade da razão humana (cientificista e reducionista) com crimes, barbáries e catástrofes, legitima e exige um (re)pensar dessa mesma racionalidade;

- os debates sobre a utilidade/validade do conhecimento e da técnica, discutindo problemáticas práticas, não dispensam utilidade/validade da reflexibilidade racional filosófica, sobre os usos dessa mesma técnica e de seus desdobramentos na vida prática;

- as propaladas "preferências democráticas" não isentam os homens do (re) pensar 
essas mesmas preferências, sua legitimidade e conseqüências;

- a possibilidade de admitir a polifonia e as múltiplas perspectivas das argumentações racionais, não legitimam estas sobre aquelas, sendo necessário "argumentar sobre as argumentações", buscando estabelecer sínteses superadoras, emancipatórias e comunicacionais;

- as multifacetárias perspectivas do real exigem o exercício das múltiplas possibilidades da busca do diálogo, da eqüidade ou do consenso, possível de obter-se pelo exercício filosófico argumentativo e equilibrado;

- o propalado fim da Filosofia, da História, dos valores, enfim, a renúncia a toda e qualquer concepção objetiva da razão, acarreta para a humanidade imensos perigos. Perigos tanto mais visíveis quanto mais aparecem valores menos discutíveis, neste conturbado momento histórico.

Enfim, o ressurgimento dos preconceitos, do racismo e dos nacionalismos étnicos, o reaparecimento dos fundamentalismos religiosos de toda a ordem, hostis às liberdades de pensamento, a proliferação de seitas massificadoras, a explosão geral da crueldade, da incredulidade e dos irracionalismos e das barbáries e crueldades, para não falar da mídia audiovisual, de idéias estandardizadas que anestesiam o espírito crítico; enfim, todos esses fenômenos, e outros mais, não fazem temer o triunfo, em escala mundial, de uma verdadeira regressão obscurantista?

Entendemos, nesse sentido, que a única barragem possível a erguer-se contra essa regressão à barbárie, seria uma volta aos ideais socráticos de "uma razão perquiritiva e angustiada", e a adoção reflexiva dos preceitos habermasianos de "uma razão argumentativa". Perquirimento e argumentação, consistem em práticas que, historicamente, se colocam como núcleo sustentador do que se chama "Filosofia" e necessitam ser ressaltadas pelo professor de Filosofia em suas práticas pedagógicas cotidianas.

Talvez sejam estas as ações racionais humanas mais necessárias e aptas à oferecer ao homem o fundamento universal que lhe parece faltar no atual momento histórico. Perquirimento e argumentação, sustentados em convicções éticas e epistemológicas capazes de representar uma evolução, limitada mas real, do pensar filosófico, capaz de produzir deslocamentos irreversíveis no desenrolar histórico das barbáries humanas.

Conforme Delacampagne (1997), alguns avanços significativos vêm ocorrendo no campo dos recortes filosóficos abarcados pela Ética e pela Epistemologia, com pensares filosóficos atuais e originais, refinando conceitos como "conhecimento, justiça, democracia, 
verdade e significação", com teorias críticas, que se libertam pouco a pouco do peso das ideologias e utopias cristalizadas e unificadoras que permearam o período moderno.

É tarefa de reconstrução racional difícil, mas de modo algum impossível, sendo imprescindível que o professor de Filosofia contemporâneo, pelo exercício da reflexibilidade filosófica e do pensar complexo, avance em passos largos e estabeleça sínteses superadoras sobre as opressões, os dogmatismos, os totalitarismos ou os imperialismos existentes, com seus cultos acentuados à razão técnico-instrumental, cujos efeitos destruentes se apresentam cotidianamente, expondo-se aos nossos olhos pela força das diferentes mídias comunicacionais (em seus mais diversos reality-shows).

Delacampagne (1997, p. 288) entende que "são passos à frente no longo caminho que a razão ainda deve percorrer para redefinir os seus objetivos e os seus meios de ação". Porém, a pressão exercida pela volta dos obscurantismos, as perdas de memória que o mundo ocidental parece sofrer a intervalos regulares, quanto a seus erros e barbáries, na tendência desastrosa de considerar que o fim da guerra fria (libertando o mundo do comunismo), o libertou de todos os seus males e flagelos, parece mascarar os verdadeiros problemas contemporâneos, evidenciando a natureza e a necessidade de exercícios reflexivos sobre os mesmos.

Portanto, todos esses fatores aliados, nos parecem demonstrar e fazer temer, mais uma vez, que a Filosofia não esteja à altura da missão que a desafia, pois com Delacampagne (1997, p. 288) pressupomos que:

A Filosofia, vasta catedral inacabada, interminável canteiro de obras, cujo fim
ninguém verá, nem por isso deixa de ser, hoje, o único espaço de argumentação
racional, em cujo interior nossas sociedades podem constituir ou antever o seu
futuro:... Desde que, naturalmente, elas assumam seu passado. E que tenham
menos ilusões sobre a realidade do seu presente...

Mais um amplo desafio para o pensar filosófico contemporâneo, pois a construção de uma filosofia e de uma ética para o futuro, demandará um esforço de proporções incomensuráveis e exige a conjunção de todos aqueles que solidarizam, que acreditam nas forças do humano, que fraternizam e universalizam possibilidades de superação das patologias e das mazelas do social, do econômico e do político, em seus inúmeros desdobramentos e conseqüências.

Portanto, ainda para não concluir, entendemos com Severino (1997) que, sem dúvida, o professor de Filosofia tem uma importante tarefa epistemológica no mundo contemporâneo, a qual não pode ser desenvolvida sem referência a uma antropologia fundante, bem como a uma axiologia geral. Assim, a questão do agir humano, tanto no plano ético como no plano 
político, científico ou pedagógico, não pode ser posta de lado, devendo ser pensada em reflexões aprofundadas e sistematizadas que "pensem seu tempo", não se submetendo a coerções ou coações de qualquer natureza, mas apenas abrindo-se para as reflexibilidades atuais e necessárias, objetivando melhor situá-las.

Assim, o professor de Filosofia terá como desafio maior para suas práticas pedagógicas no contemporâneo, em espaços significativos e significantes, o de "constituir-se em sujeito capacitado a constantes atitudes de abordagem direta e em ator da mediação entre o fazer científico-tecnológico, o exercício político e a ação reflexiva." Precisa constituir-se muito mais do que em sujeito capaz de uma atitude crítica e reflexiva, posicionando-se como sujeito ativo em espaços educantes e intermediadores, compreensivos e interpretativos, mediante a presença das constantes demonstrações de irracionalidade dos homens, visando superá-las.

\section{REFERÊNCIAS}

ALMEIDA FILHO, N. de. Universidade nova: textos críticos e esperançosos. Brasília, DF: Ed. UnB; Salvador, BA: EDUFBA, 2007.

ARANTES, P. et al. A Filosofia e seu ensino. Petrópolis: Vozes; São Paulo: EDUCPUC, 1995.

ARENDT, H. A condição do homem moderno. Rio de Janeiro: Prestes Pocket, 1988

CARNEIRO LEÃO, E. Aprendendo a pensar. Petrópolis: Vozes, 1977.

DELACAMPAGNE, C. História da filosofia no século XX. Rio de Janeiro: Zahar, 1997.

HABERMAS, J. Consciência moral e agir comunicativo. São Paulo: Brasiliense, 1989.

HUSSERL, E. A Filosofia como ciência de rigor. Coimbra: Ed. Atlântida, 1965

KUENZER, A. Z. A Formação dos profissionais da educação: proposta de diretrizes curriculares nacionais. Revista Educação. UFPR. p. 67-83, V. 25, n.01, 2000.

LAGO RODRIGUES, Z. A. Ciência, filosofia e conhecimento. Leituras paradigmáticas $.2^{\mathrm{a}}$ ed. Florianópolis: Elberth, 2003.

LITWIN, E. A educação em tempos de Internet. Revista Pátio. Porto Alegre: Artes Médicas, Ano V, (18), p. 147-161, ago/out, 2001.

MORAES, M. C. O paradigma educacional emergente. Campinas: Papirus, 1997.

MORIN, E. O cenário epistemológico da complexidade. Lisboa: Instituto Piaget, 1999 
Introdução ao pensamento complexo. 3. ed. Lisboa: Instituto Piaget, 2001.

. Educação e complexidade: os sete saberes e outros ensaios. São Paulo: Cortez, 2002.

RELATÓRIO DA COMISSÃO GULBENKIAN SOBRE A REESTRUTURAÇÃO DAS CIÊNCIAS SOCIAIS. 2. ed. Lisboa, Port.: Publicações Europa América, 2002

SANTOS, B. de S. Um discurso sobre as ciências. Lisboa, Portugal: Afrontamento, 1987.

SEVERINO, A. J. A Filosofia da Educação buscando o sentido Histórico e Social da Educação. Revista Educação e Filosofia, 10(20) Julho/dez. 1996 (67-75).

A Filosofia contemporânea no Brasil. Conhecimento, Política e Educação.

Petrópolis, RJ: Vozes, 1997

TOURAINE, A. Um novo paradigma para compreender o mundo de hoje. Petrópolis, RJ: Vozes, 2006.

VIEGAS FERNADES, J. Saberes, competências, valores e afectos necessários ao bom desempenho profissional do(a) professor(a). Lisboa: Plátano Editorações, 2001. VON ZUBEN, N. A. filosofia e educação: atitude filosófica e a questão da apropriação do Filosofar. Proposições. V 3, nº 2 (8) Julho de 1992 (p. 7-27).

VILASANTE, T. Redes e alternativas. Estratégias e estilos criativos na complexidade social. Petrópolis, RJ: Vozes, 2002. 